\title{
LA IDENTIDAD PERSONAL, EL DIÁLOGO Y LA EXTENSIÓN: POR QUÉ NO EXISTE EL YO SIN LOS OTROS ${ }^{1}$
}

\author{
M.A. Ignacio Moya A.*
}

\begin{abstract}
En este trabajo propongo un concepto del Yo que nos permite abordar y solucionar algunos de los problemas asociados con la identidad personal diacrónica. Esto es, en virtud de qué podemos considerar que hoy yo soy la misma persona que fui ayer. Este problema de la continuidad en el tiempo de la identidad personal tiene una larga historia en la filosofía analítica. En este sentido sostengo que la continuidad de la identidad personal en el tiempo se puede garantizar acudiendo al concepto del "yo extendido como centro de gravedad" que aquí presento. El argumento central es que una persona individual no conoce ni está en control de su identidad ya que las identidades no dependen de los individuos particulares, sino que siempre se extienden hacia fuera, hacia los otros. Es decir, la continuidad de mi identidad estaría garantizada por los otros.
\end{abstract}

Palabras clave: Andy Clark, amnesia, Charles Taylor, Daniel Dennett, David Chalmers, identidad personal, yo.

\section{PERSONAL IDENTITY, DIALOGUE AND EXTENSION: WHY THERE IS NO SELF WITHOUT THE OTHERS}

\begin{abstract}
In this paper I propose a concept of the self that allows us to address and solve some of the issues associated with problem of diachronic personal identity. That is, by virtue of what can we consider that I am today the same person I was yesterday? The problem of continuity in time of identity has a long history in analytic philosophy. I argue that the continuity of personal identity over time can be ensured by resorting to the concept of "extended self as the center of gravity" presented here. My central argument is that a person does not know and is not in control of her personal identity. Identities are not dependent on particular individuals, but always extend outward toward others. Therefore, the continuity of my identity is guaranteed by the others.
\end{abstract}

Keywords: Andy Clark, amnesia, Charles Taylor, Daniel Dennett, David Chalmers, personal identity, self.

* Universidad Andrés Bello, Santiago, Chile. Correo electrónico: ignacio.moya@unab.cl

1 Presenté un borrador de este artículo en la 62nd Northwest Philosophy Conference, 2010, Willamette University, Salem Oregon, Estados Unidos. 



\section{Introducción}

La PRIMERA Línea En el arTículo LA MENTE EXTENDIDA DE Andy Clark y David Chalmers nos pide que consideremos la siguiente pregunta: “¿Dónde acaba la mente y dónde empieza el resto del mundo?” Parafraseando esa pregunta, yo pido que se considere la siguiente pregunta: ¿Dónde acaba el yo y empieza el resto del mundo?

Tomando el ejemplo de Clark y Chalmers, la respuesta que propongo a esta pregunta es que el yo no se limita a, y no está limitada por, ninguna frontera física. Por lo tanto la definición de identidad personal que propongo aquí se basa en la premisa de que un yo nunca es reducible a un individuo en particular.

Aunque cuando pensamos en un yo tendemos a pensar en un individuo específico, argumentaré más adelante que el yo no es una persona individual, sino un sistema compuesto por un grupo de personas, por lo que siempre se extiende más allá de los límites físicos de cualquier organismo individual. Que el yo no es un individuo, sino un sistema, es una tesis que voy a defender recurriendo principalmente a dos ideas: la idea de extensión y el concepto de centro de gravedad ${ }^{2}$.

La idea de la extensión, y por lo tanto la idea de un yo extendido, tiene su génesis (como dije anteriormente) en el artículo de Andy Clark y David Chalmers La Mente Extendida. De ese escrito tomo prestada la idea de que la piel y el cráneo de una persona no representan los límites de la mente. Aunque estoy básicamente de acuerdo con Clark y Chalmers en que la mente humana no es una cosa encerrada dentro de un cuerpo, yo amplío esa intuición para argumentar que se puede decir lo mismo del yo. Esto es, no somos cosas encerradas en nuestros cuerpos y separados del mundo.

El otro concepto que voy a utilizar ampliamente en el presente artículo es el de un centro de gravedad. La aplicación de este concepto científico al yo se llevó a cabo por primera vez por Daniel Dennett en su ensayo El Yo como un centro de gravedad narrativa. Utilizo este concepto para afirmar que la persona individual en la que tradicionalmente pensamos cuando pensamos en un yo es en realidad el centro de gravedad de un sistema mayor que incluye siempre a otras personas.

2 Estoy al tanto de al menos un caso más en el que se utiliza el concepto de "centro de gravedad" para referirse a las personas. En su libro A Secular Age (2007, p. 141), Charles Taylor menciona brevemente que en nuestras interacciones con los demás, cada persona tiene un centro de gravedad. 
La imagen del yo extendido que emerge al unir estos dos conceptos se puede definir formalmente de la siguiente manera: Un Yo es un sistema que está constituido por la persona individual a la que nos referimos en un momento determinado (este individuo funciona como el "centro de gravedad" para ese sistema), además de las otras personas que giran en torno a ese individuo. En este caso, "girar en torno a una persona", significa estar involucrado en la vida de la persona en cuestión. Esta participación puede adoptar muchas formas distintas y viene en diferentes grados. Una madre está implicada en la vida de su hijo (ostensiblemente de manera cercana y fundamental). Un amigo también está involucrado. Y también lo está un vecino (tal vez de una forma más lejana y distante). Participar en la vida de alguien significa que estas otras personas influyen en mi comportamiento, que me atribuyen rasgos personales ("él es una persona muy puntual” o "él es una persona muy paciente") y saben cosas sobre mi vida y mis gustos personales ("Realmente le gusta el color azul. Es por eso que el auto que se compró el mes pasado es azul”).

Por último, en este trabajo voy a ver muy brevemente algunos ejemplos relacionados con la enfermedad de Alzheimer y con la amnesia para ilustrar por qué el yo no es una cosa personal, sino que está extendido en el mundo y por lo tanto está más allá del control de cualquier individuo en particular. Estos ejemplos, sostengo, demuestran que la identidad personal no depende de la voluntad del individuo cuya identidad está en cuestión, a menos que estemos dispuestos a renunciar a nuestros entendimientos más fundamentales de lo que significa ser un ser humano ${ }^{3}$. Luego concluiré con unas breves observaciones sobre los últimos avances en neurociencia que apoyan la teoría del yo extendido que aquí presento.

\section{Breves consideraciones históricas}

En este trabajo sostengo que un yo no se puede reducir a un individuo específico, porque un yo implica siempre más que el solo individuo cuya identidad está en cuestión. En el corazón de esta premisa se encuentra la afirmación de que la identidad personal no es una cosa privada o personal que está allí dentro de una persona en espera de ser descubierto por otros o por mí a través de la introspección.

Por lo tanto, el concepto del yo que presentamos aquí se debe entender como una alternativa a las perspectivas atomistas, cartesianas, incorpóreas y/o estrictamente privados

3 A menos que estemos dispuestos a rechazar la forma en que nos relacionamos con las personas cercanas a nosotros que tienen amnesia o Alzheimer y a menos que estemos dispuestos a desconocerlos (sobre la base de que ahora es un extraño que no conozco), entonces hay algo muy intuitivo en la idea que una persona que ya no puede reclamar una identidad por sí misma todavía tiene una identidad y esta sigue siendo, en un aspecto fundamental, la misma persona que era antes de la aparición de la enfermedad. Cuando usted cuida de su padre con la enfermedad de Alzheimer, este sigue siendo su padre a pesar de que él ya no sabe que es su padre. Esta intuición (que la persona sigue siendo, de una manera fundamental, la misma persona) alimenta, como explicaré más adelante, nuestras intuiciones más trascendentales acerca de las relaciones humanas y de la forma en que nos relacionamos con los demás y con el mundo. 
e internas del yo que se han propuesto y defendido históricamente en la filosofía. Tradicionalmente, la identidad personal de un individuo se ha pensado que depende de alguna característica particular que pertenece exclusivamente a la persona cuya identidad está en cuestión. Por ejemplo, su continuidad psicológica o física. En otras palabras, lo que determina su identidad es la permanencia de su cuerpo, su mente, sus recuerdos y/o sus estados psicológicos. Ella debe ser capaz de dar cuenta de su identidad, en uno de estos aspectos. Y si no puede, entonces empiezan a surgir enigmas y paradojas: ¿cómo podemos estar seguros que ella es la misma persona que conocí hace un mes?.

Históricamente, estos puntos de vista han sido defendidos por John Locke "quien sostuvo que la memoria cumple la función unificadora de la identidad personal”, David Hume "quien argumentó que cuando buscamos un yo nunca lo vemos, sino que sólo percibimos conjuntos de percepciones", René Descartes “que dijo que somos cosas pensantes” y más recientemente por Derek Parfit, quien toma la posición de que lo que importa no es la identidad personal en sí, sino la continuidad psicológica (lo que él llama Relación R) ${ }^{4}$.

El problema principal con todos estos puntos de vista es que requieren que el individuo tenga la capacidad de dar cuenta de su identidad. Si ella no puede, por ejemplo, acceder a su memoria "que es lo que sucede en los casos de amnesia", su continuidad como la misma persona no se puede garantizar. Tomemos el siguiente ejemplo: mi padre "que hoy tiene amnesia o Alzheimer" ya no se acuerda que es mi padre. Él ya no puede acceder a ningún hecho interno relevante que le indique que es mi padre. Ya no puede recordar nuestras vacaciones juntas el año pasado o todos los cumpleaños que hemos celebrado. Ni siquiera puedo recordar mi nombre. ¿Significa esto que ya no es mi padre? ¿Debo, en consecuencia, tratarlo como yo trataría a cualquier otro desconocido? Este dilema se conoce como el problema diacrónico de la identidad personal y establece que si mi padre ha de seguir siendo mi padre a través del tiempo, entonces él debe ser capaz de dar cuenta de la perduración de su paternidad. Debe haber algo en él que perdure y él debe poder reconocerlo. Pero, ¿qué puede ser ese algo? ¿su memoria? ¿su cuerpo? ¿la Relación R?

A continuación presento mi visión extendida del yo, ya que la raíz de la mayoría de los puzzles que surgen en la filosofía de la identidad personal se encuentra precisamente en esta idea de que la identidad personal es esencialmente un asunto interno y privado (que mi identidad depende de mí memoria o mí continuidad psicológica). De particular relevancia para esta discusión es el argumento que Stefaan Cuypers presenta en su artículo Hacia un concepto no atomista de la Identidad personal, donde plantea algunos desafíos interesantes a las teorías atomistas de la identidad personal. En ese artículo, Cuypers argumenta que muchos de los problemas asociados con la identidad personal se deben a la comprensión atomista del yo. Afirma:

4 Estas ideas son exploradas por Descartes en Meditations on first Philosophy, por Locke en An Essay Concerning Human Understanding, por Hume en A Treatise of Human Nature y, más recientemente, por Parfit en Reasons and Persons. 
Primero, el problema atomista de la identidad personal es el problema de la identidad de la primera persona. Sólo la propia persona puede conocer con certeza su propia identidad y, por tanto, establecer afirmaciones de identidad verdaderas. Porque nadie más tiene acceso a los hechos relevantes que constituyen la identidad de la primera persona. De este modo, la identidad personal atomista se considera desde el comienzo como identidad no social-la identidad de la persona considerada en aislamiento ${ }^{5}$.

Estoy de acuerdo con Cuypers en que el atomismo está en la raíz de la mayoría de los puzzles y dilemas en la filosofía de la identidad personal. Por eso, la respuesta que propongo aquí es la de un yo plural, abierto, social, extendido y dialógico que se opone al yo atomista.

\section{El yo como centro de gravedad}

De acuerdo con Dennett, el yo es un centro de gravedad narrativo. La idea principal de su argumento es que el yo no es una cosa o un objeto reducible a una forma de materia. ¿Pero qué tiene que ver un yo con un centro de gravedad? La analogía con los centros de gravedad funciona de la siguiente manera: mientras que todos los objetos tienen centros de gravedad, ocurre que dicho centro no se encuentran en ningún átomo específico o partícula subatómica. Los centros de gravedad no tienen masa ni color, no son $\cos ^{6} s^{6}$ Es imposible apuntar a, por ejemplo, algún átomo y decir "mira allí, ese es el centro de gravedad de ese libro". Esencialmente los centros de gravedad son ficciones, aunque Dennett dice que son ficciones muy útiles. Esta misma idea se aplica a la idea del yo. Para Dennett, un yo no es un objeto o una cosa que se encuentre ubicada en alguna neurona o parte específica del cerebro. Un yo, según él, no tiene masa, y no tiene color y, por lo tanto, sería una ficción. Esta es la razón por la que Dennett dice que la búsqueda de los neurocientíficos "por el asiento de la conciencia" en el cerebro es un proyecto mal concebido, ya que están buscando una cosa y, sin embargo, no hay ninguna cosa que encontrar ${ }^{7}$. Este punto es correcto y estoy de acuerdo con él. Sin embargo, mientras Dennett utiliza este argumento para luego defender la afirmación de Hume de que nadie nunca ha visto un yo y por lo tanto el yo es de una ficción "de la misma manera que un centro de gravedad es una ficción", yo sostengo que el yo no es una ficción. Entonces a pesar de que utilizo el recurso de un centro de gravedad, lo hago con dos fines específicos.

5 Cuypers, Stefaan, "Hacia una concepción no atomista de la identidad personal", Anuario Filosófico, 1993, p. 228.

6 Dennetr, Daniel, The Self as a Center of Narrative Gravity, s/p.

7 Ibid., s/p. 
Primero: dado que cada vez que pensamos o hablamos de alguien nunca pensamos en un sistema (al menos no inicialmente), entonces cabe preguntarse en ¿qué pensamos? La respuesta es que pensamos en un individuo específico y puntual. En otras palabras, cuando pensamos en un yo (en alguien) siempre gravitamos hacia un individuo específico -por ejemplo mi amiga que se llama Patricia- en lugar de un grupo de personas - por ejemplo Patricia más su familia y sus amigos-. Esta gravitación toma la forma de un movimiento del pensamiento mediante el cual nuestra atención y nuestro enfoque van dirigidos a la persona específica que nombro. Por lo tanto, cuando pienso en Patricia mis primeros pensamientos son acerca de ese individuo específico y no de las otras personas involucradas en la vida de ella (a menos que yo especifique que estoy hablando de otras personas también). Es decir, no pienso en un sistema de individuos sino que en un individuo. Pero dado que he definido el yo como un sistema de individuos, necesito especificar qué función cumple dentro de ese sistema aquel individuo específico en el que pienso (como en el ejemplo de Patricia). Mi argumento es que la persona en la que pienso cumple el rol de centro de gravedad para el resto del sistema.

Segundo, y en acuerdo con Dennett, uso la idea de un centro de gravedad con el fin de des-cosificar el yo (es decir, para argumentar que el yo no es una cosa o un objeto). Dennett señala acertadamente que los centros de gravedad son ficciones en la medida en que un centro de gravedad no es una cosa que se encuentra en algún átomo específico o cualquier otra partícula ${ }^{8}$.

Mi principal diferencia con Dennett, por lo tanto, radica en que mientras él desarrolla una teoría donde el yo ha de entenderse como un centro de gravedad de una narración ficticia, yo sostengo que el yo ha de entenderse como un centro de gravedad real - un individuo específico con un cuerpo material- que existe (o en algún momento ha existido ${ }^{9}$ ) en el mundo. De esta manera, entonces, yo sostengo que la corporalidad es una condición necesaria para la identidad personal.

Como consecuencia de ello, mi uso del concepto de un centro de gravedad está destinado a transmitir la idea de que existe un punto en el espacio que atrae a los otros, que ese punto está en el mundo y que debe ser un punto físico. Así como todos los objetos tienen un centro de gravedad que atrae, cohesiona, y le da forma y contenido a un objeto, lo mismo sucede con los yoes. Los individuos atraen a otros individuos. Y esos otros individuos

$8 \quad$ Ibid, $\mathrm{s} / \mathrm{p}$.

9 Hay un argumento interesante que hacer acerca de la permanencia de la identidad después de la muerte. Sin embargo, ese tema va más allá del alcance de este artículo y merece una exploración detallada. Resumiendo, la idea que un yo es un sistema constituido por otros yoes parece implicar que si un yo individual muere (es decir, uno de los componentes del sistema muere), el sistema en sí (el yo) puede continuar en el tiempo (aunque sea un yo distinto). El argumento aquí es que mientras hubo una persona en el mundo, después que ella muere ella puede seguir actuando como un centro de gravedad para el resto del sistema. Es decir, seguimos identificando persona $\mathrm{x}$ como $\mathrm{x}$ en virtud de que ella estuvo viva y construyó una identidad sobre la base de un diálogo con el mundo y la sociedad. En este caso, tal vez, el centro de gravedad actuaría de una manera mucho más abstracta y por lo tanto este yo podría parecerse al yo de una narración de ficción como dice Dennett. 
que son atraídos, por ejemplo, hacia mí, traen consigo su propio conjunto de conceptos, valores, emociones y expectativas acerca de qué o quién soy.

La gente, sin embargo, no sólo atrae a otros; una persona también emana. Lo que tengo en mente no es nuevo. La idea que un yo emana (que sale fuera de sí) tanto como atrae se remonta a la obra de G.W.F. Hegel. En su bien desarrollada teoría dialéctica de la autoconciencia, Hegel sostiene que un yo requiere la presencia de otro yo para que cada uno de ellos se pueda validar a sí mismo ${ }^{10}$. En otras palabras, la autoconciencia se logra cuando se opone un yo a otro yo. El proceso funciona así: dos seres se encuentran y mientras atraen al otro hacia sí, también salen activamente hacia el otro y participan en lo que Hegel llamó una "lucha a muerte". El propósito de este movimiento hacia el otro, y de la lucha que se desencadena, es el de despertar la conciencia del sí subyugando y negando la otra conciencia. Este sometimiento y negación del otro es necesario debido a que el yo se afirma negando al otro. Yo no soy tú. Por eso sé que soy yo.

Para Hegel, cada yo intenta obtener poder sobre el otro no sólo con el fin de someterlo una vez y conseguir poder sobre él, sino que lo hace con el propósito de retener al otro bajo un control continuo. La relación que se establece entre el que domina (el amo) y el dominado (el esclavo) es lo que Hegel llamó la dialéctica "amo-esclavo". Tener un esclavo hace posible que el amo pueda tener alguien que pueda negar continuamente. Tener un esclavo me permite decir "tú no eres yo y por eso sé que yo sí soy yo".

Los centros de gravedad que estoy describiendo en este artículo, sin embargo, intentan lo contrario. Es decir, no quieren negar al otro. Ellos quieren atraer al otro con el fin de asegurarse que ese otro les proporcione una identidad de manera positiva. No es suficiente que el otro me recuerdo que yo no soy él. Ellos deben participar activamente en el otorgamiento de mi identidad. Esta participación activa del otro en nuestra identidad no tiene que ocurrir, como veremos más adelante, de manera fácil, consensuada o armónica. Puede ser exactamente lo contrario: una lucha compleja y un gran choque de voluntades.

Charles Taylor argumenta que las identidades personales son dialógicas ${ }^{11}$. Taylor, y Hegel aún más, deja en claro que el diálogo con los demás a menudo se convierte en una lucha. Como centros de gravedad, no sólo atraemos a los demás, sino que al mismo tiempo nos resistimos a la atracción de los demás. De esta manera se produce un tira y afloja. En términos concretos, esto significa que a menudo nos resistimos a ser identificados y/o clasificado por otros. Nos resistimos a su influencia y al poder que tienen sobre nuestra identidad personal. En un esfuerzo por afirmar nuestra propia individualidad, negamos el

10 Para una explicación más detallada de este proceso dialéctico que posibilita la autoconciencia, ver la Fenomenología del Espiritu de Hegel, secciones 178 a 196.

11 Taylor argumenta que las ideas del "diálogo" y el "reconocimiento" son esenciales para la identidad personal y cultural. Mientras que él defiende esta idea en varios lugares, su ensayo La Politica del Reconocimiento proporciona un punto de partida ideal. 
poder de los demás sobre nosotros mismos. Debido a que la esencia de un centro de gravedad es atraer, cuando dos centros de gravedad se juntan el más potente a menudo le gana al otro. Como consecuencia de esto, el centro de gravedad más fuerte es capaz de ejercer un mayor control sobre su identidad, un proceso que es similar a la "lucha a la muerte" de Hegel en que uno trata de imponer su voluntad sobre el otro.

Como centros de gravedad, esto es lo que hacemos -atraemos a otros con el fin de retenerlos en nuestras vidas, en nuestras órbitas. Esta necesaria unión con el otro es la condición ineludible de la identidad personal y es precisamente lo que significa ser un yo dialógico que siempre está en el mundo.

\section{El yo extendido}

En el centro de la tesis de la mente extendida está la afirmación de que la mente no se detiene en el cráneo o la piel de una persona. Emulando la dialéctica de Hegel, Clark y Chalmers afirman que:

En estos casos, el organismo humano se ve unido a una entidad externa en una interacción en dos direcciones, que crea un sistema ensamblado que podemos considerar un sistema cognitivo por derecho propio. Todos los componentes del sistema juegan un papel causal activo, y gobiernan conjuntamente la conducta, del mismo modo que lo hace la cognición usualmente. Si eliminamos el componente externo del sistema de competencia conductual, es como si elimináramos una parte del cerebro mismo. Nuestra tesis es que este tipo de proceso ensamblado es igualmente un proceso cognitivo, ocurra completamente dentro o no, de la cabeza ${ }^{12}$.

El punto principal aquí es que la mente no está encerrada dentro del cráneo o la piel de la persona. Sin embargo, lo que se dice no es sólo que la mente sale hacia al mundo externo. La tesis es mucho más fuerte que eso y dice que la mente de hecho consiste en un sistema acoplado que incluye el cerebro individual y el mundo exterior. El argumento central es que la mente está en constante acoplamiento con el mundo con el fin de ampliar la cognición. Pensemos en computadores portátiles, mapas, libros e incluso un lápiz y un pedazo de papel. Yo guardo información, por ejemplo el nombre de una persona, ya sea en mi cerebro (mi memoria) o en alguna parte del mundo exterior, por ejemplo, escribiendo el nombre en un pedazo de papel. Dónde yo guardo esa información importa poco. Lo que importa es que yo tenga acceso a esa información cuando la necesite.

La tesis de la mente extendida afirma, también, que este acoplamiento entre el mundo individual y el externo no ha de entenderse como una acción opcional por parte de una 
mente que se encuentra originalmente aislada del resto del mundo. Por el contrario, este acoplamiento es "son parte del conjunto básico de recursos cognitivos que siempre llevamos con nosotros en el mundo"13. En otras palabras, Chalmers afirma que la evolución ha favorecido un modelo de la mente que explota los recursos externos y que se acopla de forma activa con estos a fin de mejorar la cognición.

En esta misma dirección, el concepto del yo extendido opera moviendo la identidad personal más allá del cráneo y la piel hacia el mundo con el fin de formar un sistema con los otros. De la misma manera, esta extensión del yo no ha de entenderse como algo opcional, algo que podemos decidir hacer o no. La extensión es una condición ineludible de la individualidad. Nos extendemos hacia los demás porque sin los demás, no somos. Ante la pregunta, “¿qué es un yo”, recuerden que propuse la siguiente respuesta: Un Yo es un sistema que está constituido por la persona individual a la que nos referimos en un momento determinado (este individuo funciona como el "centro de gravedad" para ese sistema), además de las otras personas que giran en torno a ese individuo. Lo que sigue ahora es una representación gráfica de dicha definición:

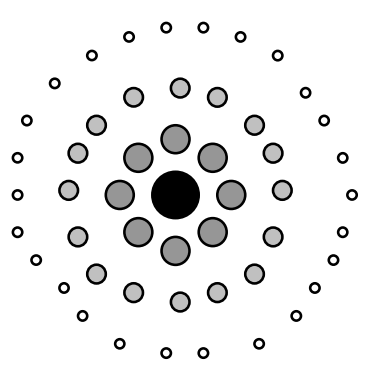

En el centro se encuentra la persona cuya identidad está en cuestión. Como el centro de gravedad que ella es, el resto de las personas que forman parte de su vida giran y giran a su alrededor (debemos tomar cada círculo como una persona). Los más cercanos a ella son los que la conocen mejor o, por ejemplo, las que se preocupan más de ella. Estas personas podrían ser los padres, los hijos, los amigos, la pareja o cualquier otro. Cuanto más cerca estén del centro, más poder ejercen sobre su identidad. Esto significa que, por ejemplo, si yo quiero saber quién es Patricia, sería conveniente averiguar acerca de los rasgos más sobresalientes de su personalidad. Y para conocer dichos rasgos, lo más conveniente sería preguntarles a las personas más cercanas a ella porque ellos son precisamente los que mejor la conocen.

Tomados todos en conjunto, estas personas (el centro de gravedad más los que giran alrededor de ella) forman un yo y por lo tanto todos cumplen una función fundamental en el otorgamiento de una identidad al centro de gravedad. Ellos son los que le dan un sentido

13 Ibid., sección 3. 
de individualidad e identidad a dicho centro. Es por eso que con otras personas distintas girando a su alrededor, el centro de gravedad tendría una identidad diferente y por lo tanto sería un yo diferente.

\section{Observaciones sobre la corporalidad, ser-en-el-mundo y la identidad personal}

La función que el mundo tiene en la formación y conformación de nuestra identidad no sólo es importante o fundamental sino que es una característica ineludible de lo que significa ser un ser humano. Para entender esta importancia, hay que tener en cuenta los siguientes puntos: desde el principio de nuestras vidas somos "construidos" desde el exterior por el mundo y por las acciones de otros. Inicialmente, nada viene de desde dentro del individuo. En primer lugar, nuestros genes nos son entregados por otros (nuestros padres biológicos). Luego, estos genes determinan (o ayudan a determinar de manera importante) nuestra identidad étnica y nuestra apariencia física, así como (posiblemente) ciertos rasgos psicológicos o disposiciones. Una vez que nacemos, nuestro lugar de nacimiento, ciudad y/o país de residencia, así como nuestros nombres y la familia con la que nos formamos tampoco son decididos o escogidos por el individuo sino que son otorgados por otros.

En efecto, los bebés humanos son incapaces de afirmar o articular sus identidades por sí mismos ${ }^{14}$. La capacidad de tener una identidad única que los distinga de otros bebés depende no sólo de la presencia de los demás, sino que requiere de la activa participación de ellos en su vida. Sin lugar a dudas, mi bebé no conoce, en primera instancia, su nombre. Tampoco sabe que el tono de su llanto es especialmente molesto cuando tiene hambre. Además, ella no sabe que es muy curiosa, y que siempre está especialmente intrigada, y constantemente atraída, por el cajón que se encuentra en la esquina izquierda de la pieza de su hermano mayor. Sin embargo, ella tiene una identidad, ella es una persona claramente distinta, única e insustituible. Esto es cierto no porque ella lo diga, sino porque somos nosotros los que lo decimos y se lo hacemos saber al mundo. Dado que yo soy parte de ella tanto como ella es una parte de mí y que como padre yo puedo afirmar con confianza que yo sé quién es, también puedo afirmar que la amaré por el resto de su vida sin la necesidad de saber a priori qué es lo que ella va a hacer con su vida ${ }^{15}$.

Todos estos aspectos (lugar de nacimiento, apariencia física, identidad étnica) son componentes esenciales e ineludibles de la identidad de cualquier individuo y sin embargo

14 Existe, también, un argumento interesante que se puede hacer sobre la identidad de los animales. Cualquier persona que haya tenido alguna vez una mascota sabe que cada animal es único e individual. Cada uno tiene su propia identidad, aunque, al igual que los bebés humanos, son incapaces de articular esas identidades. Ese tema, sin embargo, merece ser explorado en un artículo aparte.

15 En su artículo “¿Qué es lo que nuestro amor por alguien revela sobre la identidad personal diacrónica?" Fauve Lybaert aborda esta muy interesante y pertinente pregunta: ¿qué es exactamente lo que amamos cuando decimos que amamos a una persona sin saber qué o quién va a ser de esa persona en el futuro? Su respuesta es que amamos la vida de la persona. 
ninguno de ellos depende del actuar del individuo. Nosotros no decidimos dónde nacemos o cuál será nuestra lengua materna. Estos no son asuntos privados. Por otra parte, si bien es cierto que la mayoría de estos aspectos el individuo efectivamente se pueden cambiar y modificar más adelante en la vida (considere cirugías plásticas, cambios de nombre legal y otros) lo que no puede ponerse en duda es que, inicialmente, todas estas características nos son otorgadas gracias a las acciones de los demás. Vienen del mundo exterior, y por lo tanto nuestras acciones tendientes a modificar algún aspecto de nuestra identidad (apariencia física, identidad étnica) han de entenderse siempre como reacciones a las acciones de los demás. De esta manera se afirma la primacía de los otros, la primacía del mundo.

Las fronteras entre las personas no están preestablecidas, claramente definidas ni son inamovibles. Por el contrario, estos límites son flexibles, fluidos, borrosos y permeables hasta el punto de que mi propia individualidad es totalmente dependiente de la otra persona.

Es esta misma idea que argumenta Charles Taylor cuando le da al mundo y a la sociedad en la que nos encontramos en un papel fundamental en la formación de nuestra identidad. Según Taylor:

Siempre definimos nuestra identidad en diálogo con las cosas que nues-
tros otros significantes desean ver en nosotros, y a veces en lucha con
ellas. Y aún después de que hemos dejado atrás a algunos de estos otros
-por ejemplo nuestros padres-y desaparecen de nuestras vidas, la con-
versación con ellos continua en nuestro interior mientras nosotros viva-
mos $^{16}$.

Este es el aspecto dialógico tan importante para la identidad que, como afirmé al principio de este trabajo, constituye la base de la identidad personal. Este diálogo siempre requiere la presencia de los demás, y por lo tanto de una sociedad. De acuerdo con John Russon, "no se puede separar la identidad propia de la identidad de la sociedad, ya que es sólo a través de una apropiación de las propias narrativas sociales que uno desarrolla un sentido de lo que uno es" ${ }^{\text {17 }}$.

Lo que esto demuestra es que todos los debates sobre la naturaleza de la identidad personal implican necesariamente una discusión acerca de los demás y el mundo que se encuentra siempre ya habitado por los demás. Los dos (la identidad personal y de los otros) no se pueden separar, por lo que el diálogo con los demás es siempre inevitable. Aunque la intención es negar el papel de los otros en la constitución del yo, tal negación es sólo posible, como he mencionado anteriormente, después de las acciones de los demás. Es siempre una negación reactiva. En consecuencia, el mundo en el que siempre necesa-

16 TAYLOR, Charles, La Politica del Reconocimiento, 2009, p. 63.

17 Russon, John, The Human Experience, 2003, p. 71. 
riamente nos encontramos tiene en un papel primordial e innegable en la conformación de nuestra identidad personal ${ }^{18}$.

Lo que también se desprende de todo esto es que la corporeidad desempeña un papel central en la definición de nuestra identidad. Esto es porque somos vistos, individualizados, evaluados e identificados por los demás (los otros que forman la sociedad que nos encontramos) en virtud de nuestros cuerpos físicos. Nuestras identidades, en la medida en que son dialógicas, requieren que seamos individualizados (distinguidos de los demás) y esta individualización sucede en virtud de nuestros cuerpos, de nuestra presencia física. Cuando nacemos y una identidad es otorgada a nosotros, venimos a este mundo con un cuerpo. Es por eso que nuestros cuerpos no son complementos opcionales para el yo. No es que esté el yo y después a ese yo le agregamos el cuerpo. Nuestra presencia física en el mundo no es un problema que hay que resolver con el fin de llegar a una respuesta acerca de la naturaleza del yo. Por el contrario, nuestra corporalidad forma parte integral y fundamental de lo que es un yo ya que nuestros cuerpos funcionan como los centros de gravedad de nuestras identidades.

En consecuencia, así como se puede afirmar que las identidades personales no pertenecen a personas individuales, también podemos afirmar que en los casos de la enfermedad de Alzheimer o amnesia es posible mantener la identidad de un individuo en el tiempo siempre y cuando existan otros a su alrededor que estén allí precisamente para otorgar esa identidad.

\section{Alzheimer y amnesia}

Cuando los neurocientíficos hurgan más profundamente en el cerebro en busca de la sede de la conciencia a través del uso de escáneres cada vez más sofisticados, están reviviendo una versión del siglo XXI del proyecto original de Descartes. Pero esta vez no estamos buscando en la glándula pineal, están buscando algo más. Sin embargo, no importa qué tan profundo miren o cuánta más definición logren con sus máquinas, Dennett señala con razón que es un error suponer que los neurocientíficos podrán algún día decir: "Esa célula allí, justo en el medio del hipocampo (o donde sea), es el yo"19. Está claro que si hay un yo (y yo sostengo que sí hay), este no es una cosa situada dentro del individuo.

18 Para una muy interesante discusión sobre este tema, el concepto de Mit- da-sein de Martín Heidegger (Ser y Tiempo, 113) es esencial. Cuando él se refiere a nuestra relación con el mundo y a nuestra relación con los objetos hechos por personas, Heidegger señala que cuando nos encontramos con esos objetos estos siempre apuntan a la existencia de otros antes de su utilidad como objetos particulares. En otras palabras, un bote sólo puede ser un bote en la medida en que la idea de un bote siempre ya contiene en sí mismo la idea de otro (una otra persona que fabricó el bote y/o utilizará el bote para tal o cual propósito). No es que pensemos primero "bote" (objeto) y luego pensamos "persona". La idea misma de un bote sólo es posible gracias a que la idea de persona la ha precedido. Esto demuestra que para Heidegger los demás están siempre allí primero, y es por eso que ellos son existencialmente primordiales. Los otros son los que hacen posible otorgarle significados a cualquier objeto en el mundo. Quiero aplicar este mismo principio a la identidad. Esto es: los otros están allí primeros y son los que hacen posible la identidad personal.

19 Dennetr, Daniel, The Self as a Center of Narrative Gravity, s/p. 
El Alzheimer y la amnesia son ejemplos de por qué el proyecto cartesiano no logra captar nuestras intuiciones más profundas acerca de la identidad personal. Lo que estos casos (el Alzheimer y la amnesia) tienen en común es que con ellos el individuo ha perdido la capacidad para llevar a cabo el proyecto cartesiano. En otras palabras, ella ha perdido la capacidad de introspección, no puede acceder a su yo fundacional y por lo tanto no puede afirmar activamente su identidad. Y si la identidad personal fuese un asunto intrínsecamente interno, privado, cartesiano y atomista, entonces estaríamos autorizados para concluir que una persona con Alzheimer ya no sería una persona. O al menos no sería la misma persona que era antes de la aparición de la enfermedad. En efecto, el argumento indica que si la persona en cuestión no puede afirmar que su identidad es x (por ejemplo, mi padre) entonces esa persona ya no sería x. Sin embargo, esto parece ir en contra de la forma en que vivimos y nos relacionamos con los demás en el mundo. Es evidente que para la mayoría de nosotros, una persona que tiene la enfermedad de Alzheimer o amnesia sigue siendo esencialmente la misma persona que conocíamos. Seguimos cuidando, amándo y llamándola con el mismo nombre. Aunque ella ya no puede reclamar una identidad para sí, somos nosotros los que tenemos esa capacidad de mantener su identidad.

Especialmente revelador es el caso de las personas con amnesia retrógrada. Es decir, la amnesia donde la gente no tiene recuerdos de su pasado ni de su identidad, pero son capaces de formar nuevos recuerdos. Pero, de acuerdo con lo que he venido argumentando hasta ahora, resulta que tener amnesia retrógrada no implica que la persona ya no es quién era antes de la aparición de amnesia. Ella sigue siendo, por ejemplo, mi hermana pequeña. Aunque ella ya no sabe que es mi hermana, lo sigo haciendo. Y también lo saben los demás que giran a su alrededor. Como un yo extendido que ella es, su individualidad está asegurada en virtud de su ineludible interrelación con los que la rodean. Es por eso que los otros que giran en torno a ella harán un gran esfuerzo y todo lo posible por decirle, en efecto recordarle, la persona que ella es. Esto demuestra que los otros son los guardianes y poseedores de sus recuerdos y son también la fuente de su individualidad, de su identidad. En consecuencia, le mostrarán y le dirán, entre otras cosas, cuál es su nombre. Cuál es su color favorito. Qué música le gusta y le disgusta. Cómo le gusta vestir. Qué comida le gusta. Quiénes son sus amigos. Si ella es divertida o no. O si normalmente amanece de mal humor por la mañana. Tal vez es buena para contar chistes. Tal vez no. Ellos le van a decir cuáles son sus preferencias políticas. Lo que todo esto demuestra es que sólo tenemos que ir a otros para saber quién es mi hermana. Increíblemente, pareciera que no es necesario conocer a mi hermana directamente para conocer a mi hermana.

Teniendo en cuenta todo lo anterior, ¿en qué sentido podemos hablar de nuestras identidades como algo que es efectivamente "nuestro"? ¿Cómo puedo decir que mi identidad es mía? La respuesta que he propuesto es que la identidad no es mía. No es algo que yo poseo, que me pertenece o algo que debo encontrar dentro de mí a través de la introspección. La razón por la que podemos seguir diciendo que persona $\mathrm{x}$ con amnesia sigue siendo persona x (a pesar de su incapacidad para reconocerse a sí misma como x) es que ser x no está determinado por su capacidad para auto-definirse como persona x. Un yo siempre se 
extiende hacia el mundo con el fin de formar un gran sistema de identidad que es similar a la noción de la mente extendida presentada por Clark y Chalmers.

\section{Consideraciones finales sobre la extensión: la ética y la neurociencia}

Llevada a su conclusión lógica, el yo extendido tiene implicaciones para el ámbito político y ético ${ }^{20}$. Esto se debe a que -basado en el concepto del yo extendido- es posible construir un argumento en torno a la idea de que, por ejemplo, la empatía no puede ser reducido a una simple identificación emocional que el yo tiene con otro yo distinto y separado. Más bien la empatía debe ser interpretada como un reconocimiento de que lo que está ocurriendo al otro también me está pasando a mí.

Consideremos las emociones y sentimientos. Estos constituyen elementos fundamentales de nuestra identidad. Y en la medida en que, según el concepto del yo extendido, nuestras identidades están siempre ahí fuera en el mundo, entonces debemos concluir que nuestras emociones también están ahí fuera en el mundo. Así, cuando alguien cercano a nosotros siente dolor, está en peligro o se siente feliz, ese dolor o la felicidad que nosotros también sentimos (lo que se conoce como empatía) no debe ser entendida como una emoción distinta, separada de la emoción que está experimentado el otro. Esa emoción que el otro siente, y que nosotros también sentimos, es una misma emoción. La felicidad que el otro siente es nuestra felicidad; es una emoción que realmente nos está sucediendo a nosotros de manera directa (y no indirecta como sugiera la empatía). En otras palabras, no estamos simplemente identificándonos con otro dolor. Lo que ocurre es que el otro dolor es nuestro dolor. Esto es particularmente cierto cuando se trata de las personas más cercanas a nosotros, como hijos, hijas, parejas, amigos y seres queridos (los que serían las personas más cercanas al centro de gravedad en la representación gráfica del yo extendido que proporcioné en las páginas anteriores).

Cuando mi hijo experimenta un fracaso o un éxito, como padre yo experimento ese éxito como si realmente fuese mi propio éxito. Sólo después de la experiencia es que se hace posible hacer una separación y una distinción que entre mi hijo y yo. Sólo después del éxito de mi hijo puedo yo separarme de él y reconocerle el mérito y el reconocimiento que él como un individuo distinto a mí se merece ${ }^{21}$. Este reconocimiento posterior de su

20 Escribí un artículo que aborda precisamente las consecuencias éticas que se desprenden del yo extendido, que se titula La Moral ineludible: ¿dónde está mi frontera y dónde empieza el otro? y fue aceptado en el Congreso What is Morality? realizado en la Universidad VU, Amsterdam, Holanda, 2011. En cuanto a las ramificaciones políticas, estas merecen una exploración detallada en otro artículo. Sin embargo, algunas ideas preliminares indican que la teoría del yo extendido va en contra de las teorías del contrato social y de las perspectivas atomistas de la sociedad.

21 De hecho, este tema plantea algunas preocupaciones psicológicas fundamentales. Existen casos donde algunos padres viven sus vidas a través de las vidas de sus hijos y no pueden separarse de ellos. Estos casos sirven para demostrar cuán borrosa, débil e indefinible son los límites entre las personas. A menudo es muy difícil establecer límites bien definidos entre las personas, en particular con los que están tan cerca de nosotros. Estos temas, sin embargo, van más allá del ámbito específico de este artículo y merecen una exploración más detallada. 
éxito como algo suyo y no mío, puede ocurrir casi inmediatamente después del evento o, en algunos casos, se puede necesitar periodos más largos de tiempo. Cualquiera sea el caso, lo que no hago es primero reconocer su éxito como individuo y luego proceder a interiorizar ese éxito externo para internalizarlo con el fin de posibilitar una identificación emocional con mi hijo. En un principio no hay un otro. Al principio estoy sólo yo extendido hacia mi hijo. Somos uno y vivimos las mismas emociones como un solo yo. Por lo tanto, sólo después de que vivo esta conexión primordial, trascendental e ineludible con mi hijo es que se hace posible separarme de él y ver a mi hijo como un individuo separado de mí.

Los recientes avances en neurociencia le dan crédito a mi argumento de que lo que ocurre con los demás realmente nos sucede a nosotros. Aunque la tesis del yo extendido que he presentado aquí acomoda muy bien le idea que estamos siempre conectados a los demás, la neurociencia apela a la existencia de las neuronas espejo para explicar por qué nos sentimos tan estrechamente unidos y emocionalmente involucrados en la vida de aquellos que nos rodean. De acuerdo con la teoría de las neuronas espejo, cuando una persona ve a otra persona actuar, ciertas neuronas en la persona que presencia el acto "ubicados en la circunvolución frontal inferior ${ }^{22}$ se activan como si no sólo se estuviese observando la las acciones del otro, sino que en realidad se estuviesen llevando a cabo dichas acciones (lo que constituye una forma de imitación virtual y encubierta). Esto significa que cuando vemos a otra persona llorar, nuestras neuronas espejo se activan como si nosotros estuviéramos llorando. En efecto, estas neuronas se activan cuando somos nosotros los que lloramos y cuando vemos a otra persona llorando. Para estas neuronas no existe la diferencia en tú y yo. Somos uno. Estas neuronas rompen los límites entre yo el otro. Para estas neuronas no hace ninguna diferencia si lloro yo o llora ella. Robert Krulwich lo dijo muy bien cuando dijo que estas neuronas "no notan la diferencia entre ver algo y hacer algo "o más intrigante aún, que para estas neuronas, ver a alguien hacer algo es como hacerlo tú mismo"23.

Para la neurociencia, estas neuronas espejo proporcionan una explicación plausible de nuestros sentimientos de empatía. Sin embargo, este intento de explicar la empatía sigue basándose en la idea de que el yo es esencialmente un individuo atomizado que luego se conecta con los demás. En efecto, esta explicación científica supone que primero hay un yo, y luego está el otro y, finalmente, ocurre una actividad neurológica muy específica que explica la empatía. Sin embargo, el argumento que he venido desarrollando a lo largo de este artículo no permite reducir la empatía a cualquier tipo de teoría fisicalista. Mi tesis es

22 Kilner, James, et al., "Evidence of Mirror Neurons in Human Inferior Frontal Gyrus", The Journal of Neuroscience, 29(32), 2009, pp. 10153-10159.

23 Robert Krulwich es el anfitrión de un documental que se emitió en PBS sobre el tema de las neuronas espejo. En un momento del documental Krulwich le hace la siguiente pregunta al profesor de la UCLA, Marco Iacobini: "¿Usted está diciendo que hay un lugar en mi cerebro, que ... cuyo trabajo es vivir en la mente de otras personas, vivir en los cuerpos de otras personas? Su respuesta: "Así es.". En otras palabras, existen partes de nosotros (algunas neuronas) que viven fuera de nuestro cuerpo y al interior de los cuerpos de los demás. 
mucho más fuerte que eso. He argumentado que como yoes somos esencialmente sociales, plurales y extendidos. Por lo tanto, nuestra empatía no se puede explicar apelando cierta actividad neuronal específica que está encerrada en el interior del individuo, escondido debajo de la piel y el cráneo. Por el contrario, mi argumento es que nuestra empatía sólo puede explicarse apelando a una forma específica de ser-en-el-mundo, que implica necesariamente la perspectiva del yo extendido que he desarrollado aquí. Como hemos visto, este punto de vista sostiene que en la medida en que el otro siempre tiene la llave de mi identidad personal, entonces también tiene una parte de mi vida emocional por lo que mi vida emocional es su vida emocional y vice-versa. Esto es lo que me permite afirmar que, dado que estoy extendido hacia ella y soy una parte de ella, todo lo que sucede en su vida emocional también me pasa a mí. En esto consiste la empatía; en una vida compartida, común e ineludiblemente conectada.

\section{Conclusión}

En conclusión, entonces, el concepto del yo extendido que he presentado aquí ofrece soluciones plausibles a ciertos enigmas que surgen en la filosofía de la identidad personal. En particular el problema diacrónico de la identidad personal y los puzles que surgen en los casos de Alzheimer o amnesia. He argumentado en contra de los puntos de vista cartesianos y atomizados del yo y en favor de un yo social, extendido y siempre dependiente de los demás. Si podemos hablar de la permanencia y continuidad de la identidad personal sólo podemos hacerlo gracias a la participación activa de los otros en nuestras vidas. De esta manera, he ofrecido una solución al problema diacrónico de la identidad personal. En definitiva, no hay un yo sin el otro.

El yo extendido que he defendido también acomoda nuestras intuiciones y nuestros entendimientos más fundamentales acerca de las formas en que nos relacionamos con las otras personas y con el mundo que nos rodea. Vimos que en los casos cuando alguien no es capaz de afirmar una identidad para sí, las demás personas nos apuramos en llenar el vacío, le otorgamos una identidad y nos aseguramos que, por ejemplo, mi hermana con amnesia pueda seguir siendo mi hermana a través del tiempo (ofreciendo así una posible solución al ya mencionado problema de la identidad diacrónica).

Más recientemente, la neurociencia está comenzando a ofrecer nuevas perspectivas científicas acerca de las intrincadas y elaboradas redes de interconexiones que existen entre las personas. En virtud de las neuronas espejo, ahora tenemos una teoría científica que muestra exactamente qué es lo que ocurre dentro de la cabeza de un individuo cada vez que este observa a otro actuar en el mundo. Y la imagen que surge es una donde el yo está conectado fundamental e ineludiblemente con el otro de tal manera que sus acciones pasan a ser también mis acciones. La unión con el otro es tan profunda que, a nivel neurológico, no hay diferencia entre que sea yo el que le pegue a una pelota de tenis o que 
Ignacio Moya A.

yo sólo vea a Rafael Nadal hacerlo. La frontera entre Nadal y yo ya no está tan clara y definida como antes se pensaba ${ }^{24}$ *

\section{Bibliografía}

Chalmers, David y Clark, Andy, The Extended Mind, 12 Mayo 2012, disponible en: http://consc.net/papers/extended.html.

, “La Mente Extendida", trad. de Eva Aladro, 2 Junio 2013, http:// pendientedemigracion.ucm.es/info/per3/nueva_web_eva/material_para_descargar/menteextendida.pdf.

Cuypers, Stefann, "Hacia una concepción no atomista de la identidad personal", Anuario Filosófico, Depósito Académico Digital Universidad de Navarra, Universidad de Navarra, 12 Mayo 2012, http://hdl.handle.net/10171/63.

Dennett, Daniel, “The Self as a Center of Narrative Gravity”, Tufts, 12 Mayo 2012, http:// ase.tufts.edu/cogstud/papers/selfctr.htm.

Descartes, René, Meditations on First Philosophy, trad. de Michael Moriarty, Oxford University Press, Oxford, 2008.

Hegel, G. W. F., Phenomenology of Spirit, trad. de A.V. Miller, Oxford University Press, New York, 1977.

Heidegger, Martin, Being and Time, trad. de Joan Stambaugh, Suny, New York, 1996.

Hume, David, A Treatise of Human Nature, Oxford University Press, Oxford, 2000.

KiLner, JAMEs M. ET AL., "Evidence of Mirror Neurons in Human Inferior Frontal Gyrus", The Journal of Neuroscience, 29(32), 2009, pp. 10153-10159.

Krulwich, RoBert (Narr.), “Mirror Neurons”, Nova, PBS Television. 15 June 2010, http:// www.pbs.org/wgbh/nova/sciencenow/video/3204/w01-220.html.

24 Me gustaría agradecer especialmente al Profesor Ashwani Peetush (Universidad Wilfrid Laurier, Canadá) por el tiempo que se tomó para leer mi artículo y proporcionar valiosas sugerencias. También me gustaría dar las gracias a todas las personas que se acercaron a mí después de mi presentación en el 62nd Congreso Anual de Filosofía del Noroeste (que tuvo lugar en la Universidad de Willamette, Oregon, Estados Unidos) y que me ofrecieron valiosos comentarios.

* Artículo recibido: 30 de junio de 2013. Aceptado: 27 de agosto de 2013. 
Locke, John, An Essay Concerning Human Understanding, Oxford University Press, Oxford, 1975.

Lybaert, Fauve, "What Does our Love for Someone Reveal about Diachronic Personal Identity", Philosophical Frontiers, Vol. 4(2), 2009, pp. 31-39.

Parfit, Derek, Reasons and Persons, Oxford University Press, Oxford, 1986.

Russon, John, The Human Experience, Suny, Albany, 2003.

Taylor, Charles, El Multiculturalismo y la Política del Reconocimiento, Fondo de Cultura Económica, México, 2009.

A Secular Age, Harvard University Press, Cambridge, 2007. 